УДК 656.256: 681.32

\title{
ДОСЛІДЖЕННЯ МОДЕЛІ ТОЧКОВОГО КОЛІЙНОГО ДАТЧИКА В СИСТЕМАХ ПІДРАХУНКУ ОСЕЙ
}

К-т техн. наук О.В. Нейчев, магістрант А.В. Сербін

\section{ИССЛЕДОВАНИЕ МОДЕЛИ ТОЧЕЧНОГО ПУТЕВОГО ДАТЧИКА В СИСТЕМАХ СЧЕТА ОСЕЙ}

К-т техн. наук О.В. Нейчев, магистрант А.В. Сербин

\section{EXPLORATIONS INTO THE REPLICATION OF A TRACK POINT SENSOR FOR WHEEL COUNTING SYSTEMS}

\section{Cand. of techn. sciences O. Neychev, master student A. Serbin}

У роботі представлена модель взаємодї гребеня колеса $і$ чутливого елемента датчика. Очінюється вплив розмірів чутливого елемента датчика та максимально допустимого зміщення гребеня в площині, перпендикулярній напрямку руху поӥзд, на коефіиієнт індуктивного зв'язку в схемі «гребінь-датчик».

Ключові слова: коефіцієнт індуктивного зв'язку, котушка точкового колійного датчика, системи підрахунку осей, індуктивно зв'язані котушки, технічний параметр датчика.

В работе представлена модель взаимодействия гребня колеса и чувствительного элемента датчика. Оченивается влияние размеров чувствительного элемента датчика, а также максимально допустимого смещения гребня в плоскости, перпендикулярной направлению движения поезда, на коэффиџиент индуктивной связи в схеме «гребеньдатчик».

Ключевые слова: коэффищиент индуктивной связи, катушка точечного путевого датчика, системь счета осей, индуктивно связанные катушки, технический параметр датчика.

The interplay replication of an axle and sensor is presented. On the one hand, the relationship between axle shift (a plane erected to the motion) and magnetic coupling for "axle- 
sensor» circuit is substantiated. On the other hand, the relationship between redaction sensor and magnetic coupling for "axle-sensor» circuit is substantiated. A recommendation for creators of signal systems is counseled, this recommendation with regard to the erection sensor for turnout track.

Keywords: mutual coupling factor, induction-coil of a track point sensor, wheel counting systems, magnetic coupling of coils, a track sensor parameter.

Вступ.

Останнім часом, як альтернатива безперервним колійним датчикам рейковим колам, на залізницях світу все частіше застосовуються системи контролю стану колійних ділянок (СККД) на базі точкових колійних датчиків (ТКД). Оскільки виконувані СККД, а отже i датчиками, функції $\epsilon$ відповідальними, надійність роботи датчиків визначає в решті решт $\mathrm{i}$ надійність систем залізничної автоматики, до складу яких входять підсистеми СККД. Якість функціонування ТКД характеризується інтенсивністю збоїв датчиків - кількістю помилок у підрахунку осей, віднесених до загальної кількості осей, що прослідували через рахунковий пункт.

Як показує практика [1]-[3], у порівнянні з іншими пристроями СККД, на долю датчиків приходиться найбільша кількість помилок, що $\epsilon$ наслідком експлуатації ТКД в складних кліматичних умовах; впливу значних динамічних навантажень (вібрації); грозових розрядів і електромагнітних завад тягового струму; зміщення гребеня колеса в зоні чутливості датчика; появи в зоні контролю колісних пар зі значним зносом поверхні кочення.

\section{Постановка проблеми.}

Слід зазначити, що деякі типи ТКД (наприклад, фірми «Siemens», «Sel») некритичні до зміщень колісних пар перпендикулярно напряму руху. Цей факт пояснюється тим, що датчик складається 3 двох частин (генераторної і приймальної), які закріплюють із двох боків рейки [1, с.48]. При прослідуванні колісної пари над датчиком диск осі завжди виявляється між передавальною і приймальною котушками, змінюючи вихідний сигнал ТКД у необхідному діапазоні. Однак спроби створити датчик, що використовує зазначений принцип дії, для залізниць України наштовхнулися на серйозну проблему: колісні пари ряду локомотивів $\mathrm{i}$ мотор-вагонних секцій електропоїздів (ЧС4, ВЛ19, ВЛ22 і ін.) замість суцільного колісного диска мають спицевий колісний центр. При прослідуванні такого колеса у зоні дії датчика вихідний сигнал змінюється, в значній мірі, випадковим чином, ускладнюючи (або взагалі унеможливлюючи) фіксацію осей локомотивів. Не в останню чергу, тому, на мережі залізниць країн пострадянського простору найбільш розповсюдженими $\epsilon$ індукційні електромагнітні датчики інших типів - таких, що реагують на гребінь колісної пари. Для подібних ТКД зміщення гребеня колеса у вертикальній площині i горизонтальній - перпендикулярно напрямку руху, знос гребеня колеса, знос бокової частини головки рейки створюють передумови для виникнення помилок при підрахунку осей.

\section{Мета роботи.}

Теоретичне обгрунтування впливу просторового положення гребеня колісної пари відносно площини індуктивного елемента ТКД, а також габаритних розмірів останнього, на вихідні технічні параметри датчика. Вибір оптимальних розмірів котушки і складання рекомендацій на основі результатів дослідження запропонованої розрахункової моделі.

\section{Основна частина.}

За конструктивними особливостями найбільш розповсюджені ТКД можна звести до двох типів, структурні схеми яких наведені на рис.1.

В першому варіанті датчика (рис. 1,a) електромагнітне поле створюється генератором $Г$ і котушкою K1, і пронизує витки приймальних котушок К2, К3. Робоча частота генератора звичайно складає 30-50 кГц. За відсутності колеса в зоні дії датчика на геометрію поля впливають форма i розміри котушок, їх взаємне розміщення i близькість рейки. При вступі колеса в робочу зону i по мірі його прослідування над 
котушками

змінюється

взаємна

індуктивність M12 і M13, що призводить до зміни сигналу на входах приймачів ПРМ1, ПРМ2 i їх виходах. В залежності від

a)

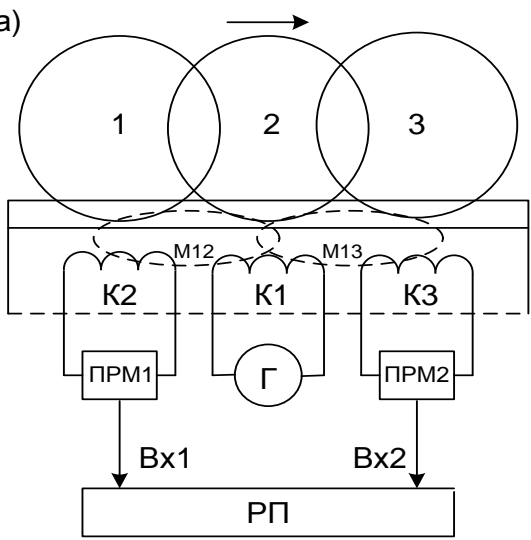

характеру i послідовності зміни напруг на входах Вх1 і Вх2 реєструючий пристрій фіксує факт прослідування осі і напрям руху колеса.

Рисунок 1 - Схеми взаємного розміщення чутливих елементів датчиків

Датчики другого типу (рис. 1 б) мають у своєму складі два практично однакових вимірювальних комплекти (ПРМ, Г, К) i реєструючий пристрій. Котушки датчика, як правило, входять до складу кола генератора, що визначає його робочу частоту. За відсутності колеса в зоні дії датчика геометрія електромагнітного поля залежить від параметрів котушок і відстані від котушок до головки рейки. Поява колеса змінює параметри коливального контуру, до складу якого входить котушка, в наслідок чого може змінюватись робоча частота генератора або напруга на його виході. Приймачі фіксують зміну вихідної величини

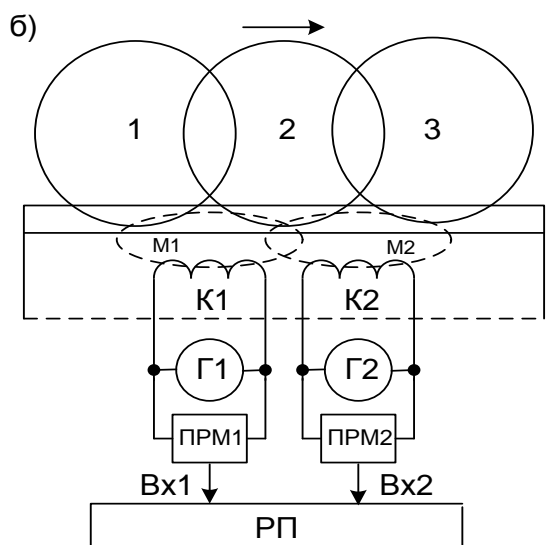

i формують на відповідних входах РП пропорційні сигнали, дозволяючи зафіксувати вісь і напрям її руху.

Механізм взаємодії гребеня колеса i чутливого елемента ТКД другого типу (рис.1,б) наведений на рис.2.

Індукований струм протікає по поверхні гребеня (рис.2,a). Оскільки гребінь колеса має малий омічний опір, можна вважати, що контур струму являє собою короткозамкнений виток. Площина, форма контуру і поверхні цього витка залежать від взаємного розташування колеса i котушки датчика і змінюються в процесі руху. a)

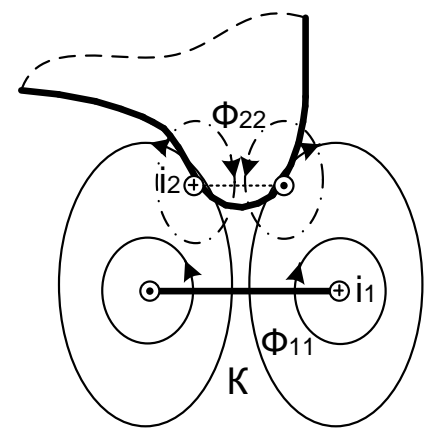

б)

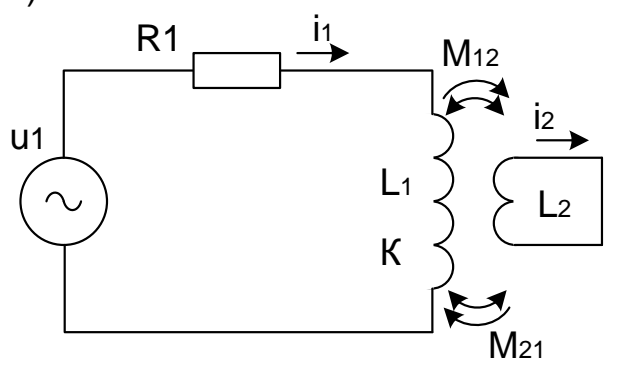

Рисунок 2 - Ілюстрації до механізму взаємодії датчика і колеса

Взаємні впливи індуктивно зв'язаних контурів можуть бути описані системою диференціальних рівнянь [4, с.107]:

$$
\left\{\begin{array}{l}
u_{1}=R_{1} i_{1}+L_{1} \frac{d i_{1}}{d t}-M_{21} \frac{d i_{2}}{d t} \\
-u_{2}=R_{2} i_{2}+L_{2} \frac{d i_{2}}{d t}-M_{12} \frac{d i_{1}}{d t}
\end{array},\right.
$$


де $M_{12}$ - взаємна індуктивність при впливі котушки 3 індуктивністю $L_{1}$ на котушку 3 індуктивністю $L_{2}, \Gamma$ н;

$M_{21}$ - взаємна індуктивність при зворотному впливі $\left(L_{2}\right.$ на $\left.\left.L_{l}\right)\right)$, Гн.

В свою чергу, ступінь зв'язку між котушками $L_{1}$ i $L_{2}$ характеризують коефіцієнтом зв'язку [5, с.114]:

$$
k=\sqrt{\frac{M_{12} M_{21}}{L_{1} L_{2}}},
$$

Підставимо друге рівняння системи (1) у перше за умови $R_{2} \rightarrow 0$ i $u_{2} \rightarrow 0$, a також, використовуючи (2), одержимо:

$$
u_{1}=R_{1} i_{1}+\left(1-k^{2}\right) L_{1} \frac{d i_{1}}{d t}
$$

Рівняння (3) описує характер взаємодії гребеня колеса й обмотки датчика 3 індуктивністю $L_{l}$. При відсутності колеса коефіцієнт зв'язку $k=0$, що визначає максимальну індуктивність вимірювальної системи $\mathrm{i}$ мінімальний струм $i_{1}$, який протікає у обмотці. В міру наближення колеса $k$ стає більше нуля, зменшуючи результуючу індуктивність системи зв'язаних контурів. Коефіцієнт зв'язку досягає максимального значення в момент перебування гребеня колеса над центром котушки ТКД. Якщо зневажити деякою несуттєвою зміною індуктивності $L_{1}$ за рахунок зміни еквівалентної магнітної проникності середовища в системі зв'язаних контурів, тоді на вихідну величину $u_{1}$ впливає коефіцієнт $k$, що залежить від відстані між котушкою i площиною короткозамкненого витка вихрового струму $i_{2}$, а також форми і геометричних розмірів котушки. Тобто, оптимізувавши форму i розміри котушки, можна досягти, за інших рівних умов, максимальної зміни коефіцієнта зв'язку.

Для рішення оптимізаційної задачі, необхідно визначитися 3 цільовою функцією $f$ i обмеженнями $g_{n}$ типу нерівностей i рівностей $[6$, с.251]. У розглянутому випадку, цільову функцію обмежує вісім умов $(n=8)$ :

$$
\begin{aligned}
& f\left(g_{1}, g_{2}, \ldots, g_{n}\right) \\
& \left\{\begin{array}{l}
g_{1}=\text { const }_{1} ; \\
\text { const }_{2}<g_{2}<\text { const }_{3} ; \\
\mathrm{M} \\
g_{n}=\text { const }_{n} .
\end{array}\right.
\end{aligned}
$$

Коефіцієнт зв'язку $k$, виражений через магнітні потоки взаємовпливаючих котушок $[5$, c.115]:

$$
k=\sqrt{k_{12} k_{21}}=\sqrt{\frac{\Phi_{12}}{\Phi_{11}} \cdot \frac{\Phi_{21}}{\Phi_{22}}},
$$

Відомо [7, с.189], що для випадку однорідного поля магнітний потік зв'язаний 3 магнітною індукцією співвідношенням:

$$
\Phi=B S \cos (\alpha)
$$

де $B$ - модуль вектора магнітної індукції, Тл;

$S$ - площа поверхні, що пронизується силовими лініями поля;

$\alpha$ - кут між напрямком вектора магнітної індукції і площиною поверхні.

У розрахунку залежності коефіцієнта $k$ від розмірів котушки датчика, представимо дві взаємодіючі площини (рис.3). Площина короткозамкненого витка - 3 належною їй умовною точкою $m \in(x, y)$. Сторони напівплощини $a_{2}$ i $b_{2}=b_{1}$. Площина котушки зі сторонами $\left(a_{1}+a_{1}\right) \times\left(b_{1}+b_{1}\right)$. Розглянуті перерізи утворені з'єднанням чотирьох умовних провідників $a, b, c, d$.

3 [7, с.179] відомо, що провідник кінцевої довжини зі струмом $I$, який протікає у ньому, створює навколо себе поле 3 індукцією (на прикладі провідника $b$ ):

$$
B_{b}=\frac{\mu \mu_{0} I\left(\cos \beta_{1}+\cos \beta_{2}\right)}{4 \pi \cdot r b},
$$

де $I$ - струм, який протікає у провіднику; 


$$
\frac{\mu \mu_{0}}{4 \pi} \quad-\quad \text { магнітні характеристики }
$$

середовища;

$r b$ - відстань між точкою спостереження поля і віссю провідника;
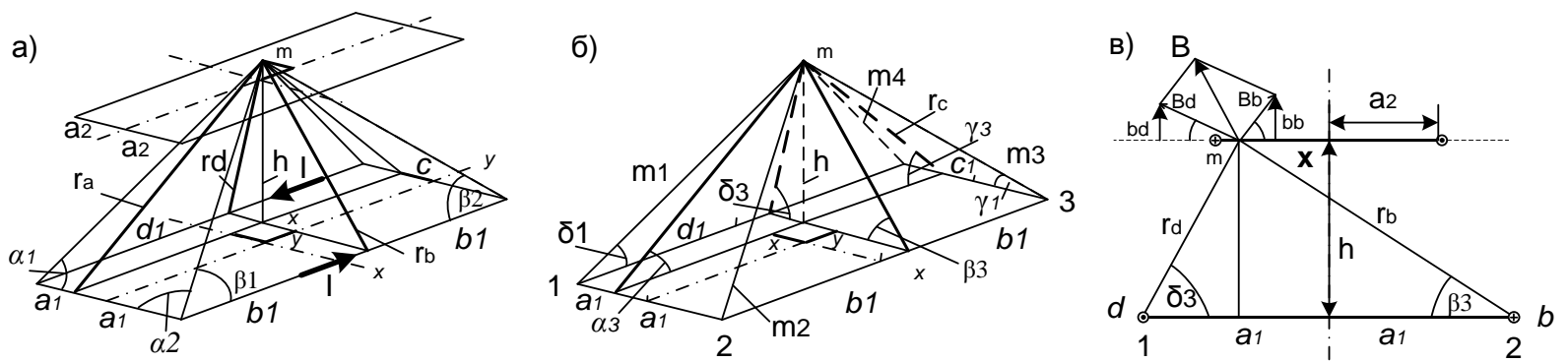

Рисунок 3 - Ілюстрація до розрахунку магнітної індукції в гребені колеса

Грунтуючись на принципі суперпозиції, рівності умов $\left(I, \mu, \mu_{0}\right)$ і тієї обставини, що величини $\cos \beta_{1}, \cos \beta_{2}, r b$ можуть бути виражені геометрично через $a_{1}$, $b_{1}, h, x, y$, магнітна індукція $B$, створена котушкою з провідників (нижня площина) у точці дослідження $m$ дорівнює:

$$
B_{(m)}=K(\mu) \cdot \sum_{i=1}^{4} B_{i}\left(a_{1}, b_{1}, h, x, y\right)
$$

$\cos \beta_{1}, \cos \beta_{2}$ характеристики положення досліджуваної точки простору стосовно кінців провідника.

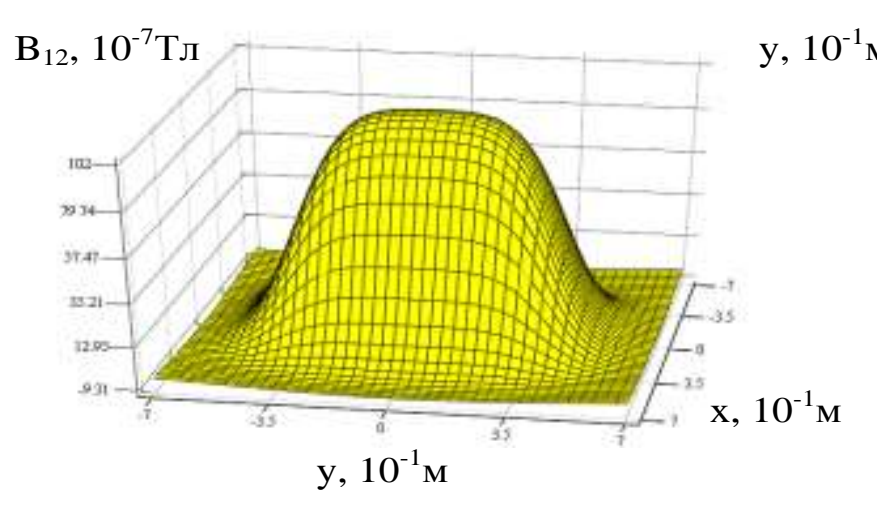

a) межами. де $K(\mu)$ - характеристика магнітної проникності середовища, в якому розраховується індукція;

$B_{i}$ - поле 3 індукцією провідників, відповідно, $a, b, c, d$.

Задаючи значення $a_{1}, b_{1}, h, x, y$ можна розрахувати $B$ у будь-якій точці, що знаходиться як у площині короткозамкненого витка так $\mathrm{i}$ за його

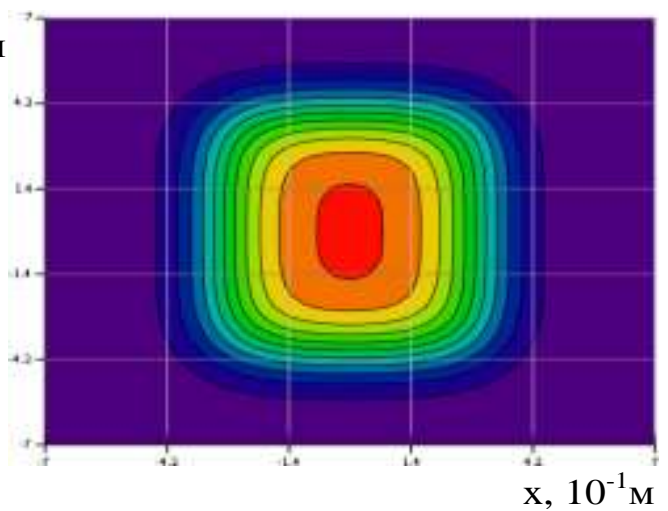

б)

Рисунок 4 - Результати розрахунку магнітної індукції, створеною котушкою з розмірами $60 \times 80$ мм, на відстані 23 мм від площини $L_{1}$

Як витікає 3 наведених на рис.4 i рис.5 графіків, створюване котушкою прямокутної форми магнітне поле неоднорідне як у площині котушки, так і на деякій відстані від неї. У випадку неоднорідного магнітного поля магнітний потік знаходять, як суму магнітних потоків, що пронизують площу кожної з ділянок, на які можна розбити досліджувану поверхню. У результаті, має місце, середнє значення індукції $B_{\tilde{n} \text { в. }}$ контурі $S$.

Таким чином, після підстановки в (5) виразу (6) з урахуванням (7)-(8) і того, що $B_{(m)}$ в (8) являє собою перпендикуляр до 
площини короткозамкненого витка, одержимо цільову функцію:

$$
k=\sqrt{\frac{B 12_{\tilde{n} \delta .}\left(x, y, a_{1}, h_{1}, b_{1}, a_{2}, \Delta\right) \cdot B 21_{\tilde{n} \delta .}\left(x, y, a_{2}, h_{1}, b_{1}, a_{1}, \Delta\right)}{B 11_{\tilde{n} \delta .}\left(x, y, a_{1}, h_{0}, b_{1}\right) \cdot B 22_{\tilde{n} \delta .}\left(x, y, a_{2}, h_{0}, b_{1}\right)}},
$$

де $B 12$ - магнітна індукція, створена $L_{1}$ у площині $L_{2}$;

$B 11$ - індукція, створена $L_{1}$ у площині $L_{1}$;

$B 21$ - індукція, створена $L_{2}$ у площині $L_{1}$;

$B 22$ - індукція, створена $L_{2}$ у площині $L_{2}$;

$h_{1}$ - відстань від площини джерела

індукції до точки, в якій розраховується індукція;

$h_{0}=0$

$\Delta$ - зміщення нульової осі площини гребеня відносно нульової осі площини датчика.

Відповідно до інструкції ЦП 0269 номінальна ширина колії - 1520 мм, однак максимальна ширина, при якій допускається експлуатація залізниць, складає 1548 мм. Відповідно до вимог інструкції ЦВ-ЦЛ-0062 відстань між внутрішніми бічними поверхнями коліс повинна знаходитися в діапазоні 1437-1443 мм, номінальна товщина гребеня колеса - 30 мм, мінімальна - 26 мм. Найгірші умови для фіксації осі будуть спостерігатися при максимальній ширині колії (1548 мм) і появі в зоні контролю колісної пари з відстанню між внутрішніми бічними поверхнями коліс 1437 мм і мінімальною товщиною гребеня (26 мм). У цьому випадку вільний простір для можливого зміщення гребеня колеса $\left(\mathrm{L}_{\mathrm{cm}}\right)$, перпендикулярно напрямку руху, складе: $\mathrm{L}_{\mathrm{cm}}=1548-1437-\quad-(2 \cdot 26)=59$ мм. Тобто, відносно подовжньої осі котушки датчика гребінь колеса може зміщуватися в діапазоні $\Delta= \pm 29,5$ мм. Очевидно, що при номінальній ширині колії $-\Delta= \pm 15,5$ мм.

На рис.6 наведене взаємне розташування гребеня колеса i котушки датчика при найгірших для фіксації умовах (з погляду віддаленості нижньої крайки гребеня від площини обмотки).

Згідно [1]-[3] поверхня датчика повинна розташовуватися нижче головки рейки на 45 мм (мінімум). Враховуючи те, що котушка повинна бути захищена від механічних i кліматичних впливів, наприклад, пластиковим корпусом товщиною 2 мм, площина котушки датчика виявиться на 47 мм нижче головки рейки. Висота гребеня колеса для всіх типів нових коліс [8] повинна складати 28 мм; мінімальна ширина, 3 урахуванням зносу 26 мм. В міру зносу поверхні кочення колісної пари гребінь буде «подовжуватися», наближаючись до датчика i полегшуючи процес фіксації осі. Тому найгірші умови будуть спостерігатися при новому бандажі 3 висотою гребеня 28 мм.

При цьому відстань між площиною котушки і нижньою крайкою гребеня складе 19 мм (47-28=19). Враховуючи те, що розподіл щільності вихрових струмів у реальному гребені не піддається аналітичному розрахунку, методом «експертних оцінок» приймемо, що еквівалентний виток знаходиться у площині в2 (рис.6,a) на відстані 4 мм від нижньої крайки гребеня, тобто, $\quad h_{1}=23$ мм (від площини котушки). Ширина перерізу короткозамкненого витка - 20 мм $\left(a_{2}=10\right.$ MM).

Рішення задачі (4) представлено в табличній формі (табл.1)

\section{Висновок.}

Як витікає 3 наведених в Табл.1 результатів максимум коефіцієнта $k$ ( $\Delta \leq \pm 10$ мм) спостерігається при ширині чутливого елемента датчика - 52 мм $\left(a_{1}=26 \mathrm{Mм}\right)$. При номінальній ширині колії і допустимому зміщенні гребеня $\Delta \leq \pm 15$ мм) рекомендованою можна вважати ширину котушки датчика 60 мм ( $a_{1=30 \mathrm{Mm})}$ при довжині 70 - 80 мм.

Для збереження оптимальних i стабільних рівнів вихідних характеристик чутливих елементів ТКД ширину котушок датчиків слід вибирати в два рази більшою, порівняно 3 максимально допуситимим зміщенням гребеня в зоні контролю, а також нормувати ширину колії в місцях встановлення ТКД, в залежності від фактичних розмірів котушок. 


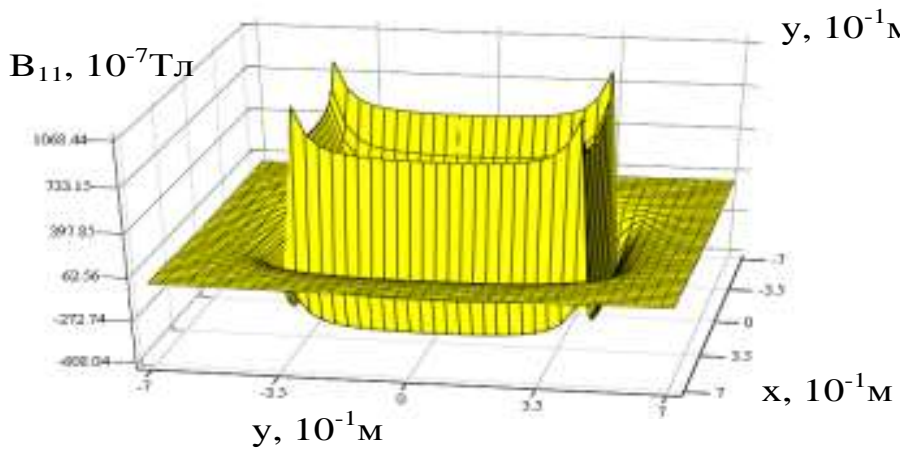

a)

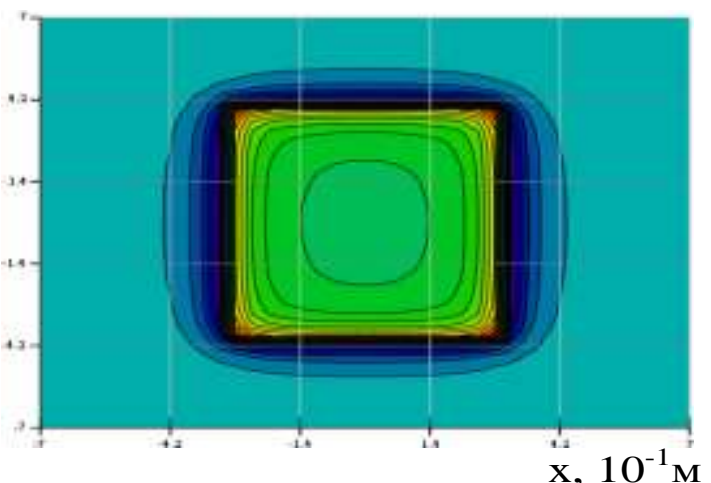

б)

Рисунок 5 - Результати розрахунку магнітної індукції, створеною котушкою з розмірами $60 \times 80$ мм, у площині котушки
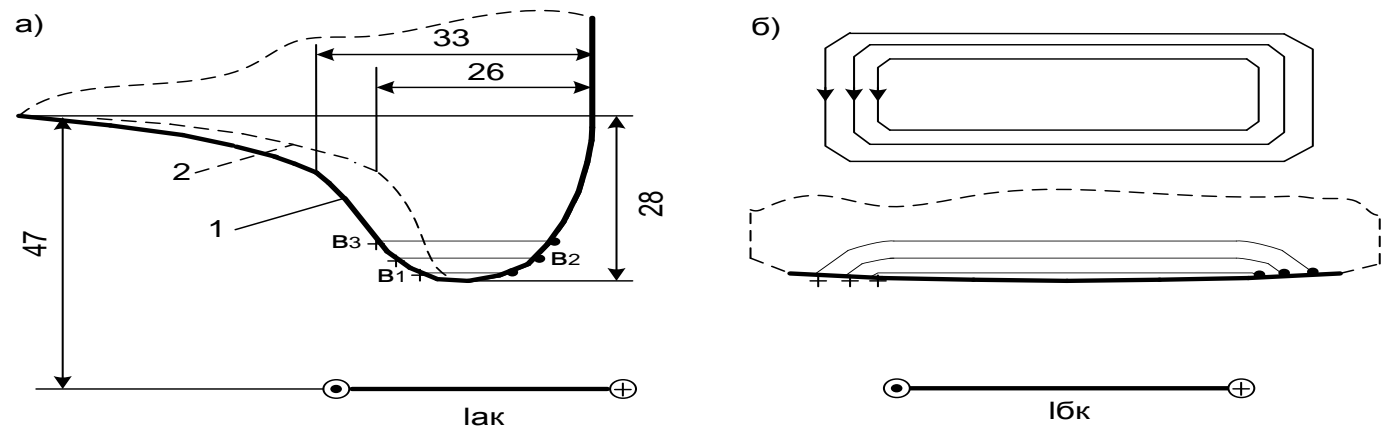

Рисунок 6 - Схема взаємного розташування гребня осі і котушки датчика

Таблиця - 1

Рішення при $h_{1}=23 \mathrm{MM}, b_{1}=40 \mathrm{MM}, a_{2}=10 \mathrm{MM}, h_{0}=0 \mathrm{MM}$.

\begin{tabular}{|c|c|c|c|c|c|c|c|}
\hline$a_{1, \mathrm{MM}}$ & $\mathrm{k}(\Delta=0) \mathrm{k}(\Delta= \pm 5) \mathrm{k}(\Delta= \pm 10)$ & $\mathrm{k}(\Delta= \pm 15)$ & $\mathrm{k}(\Delta= \pm 20) \mathrm{k}(\Delta= \pm 25)$ & $\mathrm{k}(\Delta= \pm 30)$ \\
\hline 10 & 0,083 & 0,078 & 0,063 & 0,044 & 0,026 & 0,012 & $2,7 \cdot 10^{-3}$ \\
\hline 12 & 0,093 & 0,087 & 0,072 & 0,052 & 0,032 & 0,015 & $4,5 \cdot 10^{-3}$ \\
\hline 14 & 0,101 & 0,095 & 0,080 & 0,060 & 0,038 & 0,020 & $7 \cdot 10^{-3}$ \\
\hline 16 & 0,106 & 0,101 & 0,087 & 0,067 & 0,045 & 0,025 & 0,010 \\
\hline 18 & 0,111 & 0,106 & 0,093 & 0,074 & 0,052 & 0,031 & 0,014 \\
\hline 20 & 0,113 & 0,110 & 0,098 & 0,081 & 0,059 & 0,037 & 0,019 \\
\hline 22 & 0,115 & 0,112 & 0,102 & 0,086 & 0,066 & 0,044 & 0,025 \\
\hline 24 & 0,116 & 0,113 & 0,105 & 0,091 & 0,073 & 0,051 & 0,031 \\
\hline 26 & 0,115 & 0,113 & 0,107 & 0,095 & 0,078 & 0,058 & 0,037 \\
\hline 28 & 0,115 & 0,113 & 0,108 & 0,098 & 0,084 & 0,065 & 0,044 \\
\hline 30 & 0,114 & 0,112 & 0,108 & 0,101 & 0,088 & 0,071 & 0,051 \\
\hline 32 & 0,112 & 0,111 & 0,108 & 0,102 & 0,092 & 0,077 & 0,058 \\
\hline 34 & 0,111 & 0,110 & 0,108 & 0,103 & 0,095 & 0,082 & 0,064 \\
\hline 36 & 0,109 & 0,108 & 0,107 & 0,103 & 0,097 & 0,086 & 0,070 \\
\hline 38 & 0,107 & 0,107 & 0,106 & 0,103 & 0,098 & 0,089 & 0,076 \\
\hline 40 & 0,105 & 0,105 & 0,104 & 0,103 & 0,099 & 0,092 & 0,080 \\
\hline
\end{tabular}

\section{Список використаних джерел}

1 Гофман, Г.Опыт эксплуатации и области применения напольных устройств счета осей типа ZР 43 [Текст]// Железные дороги мира.- 1993.- №1.- С. 47-50. 
2 Система счета осей фирмы Siemens и ее испытания в России [Текст]// Железные дороги мира.- 1993.- №2.- С. 60-66.

3 Минин, В.А., Лучинин В.С. Испытание счетчиков осей фирмы «Сименс» [Текст]// Автоматика телемеханика и связь.- 1992.- №11.- С. 26-28.

4 Блажкин, А.Т. Общая электротехника [Текст]: учеб. пос. для вузов/ А.Т. Блажкина. 4-е изд., перераб. и доп. - Л.: Энергоатомиздат, 1986. - 592 с.

5 Зевеке, Г.В. Основы теории цепей [Текст]: учебник для вузов/ Г.В. Зевеке, П.А. Ионкин, А.В. Нетушил. - 5-е изд., перераб. и доп. - М.: Энергоатомиздат, 1989. - 528 с.

6 Акулич, И.Л. Математическое программирование в примерах и задачах [Текст]: учеб. пос. для студентов эконом. спец. вузов/И.Л. Акулич. - М.: Высшая школа, 1986. -319 с.

7 Трофимова, Т.И. Курс физики [Текст]: учеб. пос. для вузов/ Т.И. Трофимова. - 2-е изд., перераб. и доп. - М.: Высшая школа, 1990. - 478 с.

8 Інструкція 3 формування, ремонту та утримання колісних пар тягового рухомого складу залізниць України колії 1520 мм [Текст]: ВНД 32.0.07.001-2001: нова редакція, затв. Наказом Укразалізниці від 29.05.2001.- К.: Укрзалізниця, 2011.- 171 с.

Рецензент д-р техн. наук, професор В.І.Мойсеєнко

Нейчев Олег Володимирович канд. техн. наук, доцент, кафедра автоматики та телемеханіки, Українська державна академія залізничного транспорту. Тел.: (057)730-1032. E-mail: serbin@i.ua

Сербін Артем Вікторович магістр, кафедра автоматики та телемеханіки, Українська державна академія залізничного транспорту. Тел.: (093)231-19-40. E-mail: serbin@i.ua

O. Neychev candidate of techn. sciences, associate professor, Chair of autocontrol and telecontrol, Ukrainian State Academy of Railway Transport. Tel.: (057)730-10-32. E-mail: serbin@i.ua

A. Serbin master, Chair of autocontrol and telecontrol, Ukrainian State Academy of Railway Transport. Tel.: (093)231-19-40.E-mail: serbin@i.ua 